\title{
CREENCIAS Y COSTUMBRES DE LA POBLACIÓN KRIOL EN CORN ISLAND
}

Débora Forbes Morales ${ }^{[1]}$

Beverly Hendricks Gipson ${ }^{[2]}$

Nubia Ordoñez ${ }^{[3]}$

\section{Resumen}

Este artículo se basó en la monografía de la licenciatura en Educación Intercultural Bilingüe, intitulada Historia tradicional de la población kriol de Corn Island en el ámbito de la cultura, se enfatizaron las costumbres y creencias del pueblo kriol de Corn Island. La metodología cualitativa procedió técnicamente en la acción-reflexiòn-participativa, en especial grupos focales y entrevistas individuales con personas de diferentes edades. Estas personas, además de compartir sus conocimientos, también expresaron sus sentimientos profundos alrededor de la pérdida de nuestras creencias y costumbres en las nuevas generaciones, así como de la posibilidad de revitalizarlas.

Hablar de las creencias y las costumbres tradicionales abre la posibilidad de poder expresar y practicar todo lo sagrado de nuestros ancestros. Estas prácticas permitieron a ellos vivir muchos años sin enfermedades, gozando de buena salud y tranquilidad en su vida cotidiana.

Palabras claves: creencias, Costumbres, Corn Island, Educación Intercultural Bilingüe.

\section{Introducción}

Este aporte se enfoca en el rescate y la revitalización de las creencias y costumbres de la población kriol en Corn Island, en la problemática de la perdida de los valores y tradiciones ancestrales de este pueblo.

Corn Island está compuesto por dos islas, una grande y una pequeña. La Isla Grande (Great Corn Island) está ubicada entre las coordenadas $12^{\circ} 10$ de latitud Norte y $83^{\circ} \mathrm{O} 3$ de longitud Oeste, dista aproximadamente 53 kilómetros del punto más cercano de la costa (Cabo de las Perlas) y 68 kilómetros de Bluefields en la Región Autónoma del Atlántico Sur de Nicaragua. Mide 5 kilómetros de largo y entre 2 a 3 kilómetros de ancho. La comunidad está asentada al Oeste con la isla de San Andrés, Noreste de la isla pequeña, al Norte Puerto Cabezas y al Este el Puerto del Bluff.

[1] Licenciada en ciencias de la Educación con mención en Educaciòn Intercultural Bilingüe.

[2] Licenciada en Ciencias de la Educación con Mención en Educaciòn Intercultural Bilingüe

[3] Tutora, MSc. en Estudios Interdisciplinarios. 
Debido a su ubicación privilegiada, los pobladores de Corn Island han vivido tradicionalmente de la abundancia de los recursos naturales presentes en la zona, principalmente de la pesca y la siembra. Sus primeros pobladores fueron los indígenas kukras, quienes habitaban entre las cercanías del Río Grande hasta la Laguna de Bluefields. Este subgrupo conocido generalmente como sumu que vivían en la parte baja de la isla, actualmente el barrio Brig Bay, eran cazadores, pescadores y practicaban la agricultura. El nombre de Corn Island se originó del cultivo de maíz que en inglés es "Corn" como en el lugar sembraban mucho maíz decidieron ponerlo el nombre "CORN ISLAND" que significa "Isla de Maíz". Esta comunidad de origen kriol ha ido perdiendo su cultura, tradiciones y costumbres.

Las creencias, costumbres y la cultura tradicional propias de este pueblo, influyen en la vida y las prácticas cotidianas de la gente. La investigación nos permitirá identificar algunas de estas creencias y analizarlas. El sentido es despertar el interés de la población en general para la revitalización de sus creencias, costumbres y su cultura tradicional que en su conjunto se han ido perdiendo. Creemos que esto ha afectado la pertinencia étnica del pueblo kriol.

El estudio contribuye de manera general al interés y a la revitalización del amplio y polifacético mosaico multicultural de la Costa Caribe y enriquece la cultura nacional. Además, será de mucho interés para todos los costeños que trabajan para una educación pertinente a la realidad de la Costa Caribe Nicaragüense y para el rescate del patrimonio cultural del pueblo kriol. Por ejemplo, hay leyes importantes que nos dan el derecho a mantener y desarrollar nuestra propia cultura. La Ley de Autonomía (Ley 28, 1987) establece el Régimen de Autonomía de las regiones en donde habitan las comunidades de la Costa Atlántica de Nicaragua y reconoce los derechos y deberes propios que se establece en la Constitución Política. La Ley General de Educación (Ley 582, 2006) establece que "El Sistema Educativo Autonómico Regional (SEAR) es uno de los subsistemas educativos del país dirigido y administrado por los gobiernos regionales a través de sus Secretarías de Educación. SEAR está basada en el modelo de educación intercultural multilingüe que valora las lenguas oficiales de la región."

\section{Revisión de literatura}

Se dimensiona el concepto de historia y algunas teorías en relación a la cultura y sus variables de costumbres y creencias. En la comprensión que la historia es la ciencia que tiene como objeto de estudio el pasado de la humanidad a través de los enfoques y metodologías de las Ciencias Sociales.

Se reflexiona en torno a los siguientes conceptos de cultura: 


\section{CULTURA INDÍGENA Y AFRODESCENDIENTE}

"Es el conjunto de conocimientos, saberes, principios, técnicas, leyes y representaciones simbólicas que comparten los integrantes de un determinado pueblo. Sus costumbres, ordenamiento y creencias los distinguen de los demás pueblos y culturas." (Rizo 2003, p. 26).

En la primera Jornada Indígena Centro Americana sobre medio ambiente y cultura del 24 al 29 de junio de 1996 se dijo que cultura es “...todo lo que nos rodea. Es toda la riqueza material y espiritual de un pueblo (Memoria, p. 111).

El término y realidad de cultura es polivalente según conceptualizó Mario Rizo en distintas dimensiones en el devenir histórico (2003, p.13, 14).

Según el antropólogo Paolo Venezia (2003, p. 33), en el entramado sociohistórico la lengua y cultura están estrictamente vinculados. Cuando una comunidad lingüística requiere entablar relaciones con otra comunidad lingüística, se vuelve bilingüe sin que por ello tenga que sustituir o dejar su lengua por otra. La Educación Intercultural Bilingüe permite que, sobre la base de lo propio, el educando y la comunidad a la que pertenecen estén en mejores condiciones de relacionarse con lo ajeno y de abrirse a nuevos conocimientos, valores, saberes y forma de interpretar la realidad.

Según Hodgson (2007) la costumbre es "la manera de obrar establecida por una larga práctica o adquirida por repetición de actos de la misma especie." Y, la tradición como la fuente de "la transmisión hecha de generación en generación de hechos históricos, doctrinas, leyes, costumbres, etc." En la investigación estaremos buscando esas maneras de producir de los kriol. Sabemos que, otros grupos étnicos han adaptado algunas de las costumbres kriol, por ser la mayoría. Por ejemplo, en Corn Island se cocina todo tipo de comida con coco, inclusive se toma café con crema de coco. De igual manera entenderemos por creencias "el firme consentimiento y conformidad con una cosa."

Actualmente en el ámbito educativo lo tradicional tiene distintas valoraciones positivas, cuando se trata de conocimientos prácticos relacionados con la tradición ancestral (como el caso de la medicina tradicional); sin embargo, para la educación intercultural la tradición de los pueblos representa una fuente de inspiración y sabiduría indispensable para su desarrollo cultural." Es por eso que en el proceso de desarrollo curricular y la elaboración de textos se hace necesario retomar y plasmar todos estos aspectos como contenidos de estudio (Venezia, 2003, p. 52).

La cultura de un pueblo es uno de los elementos esenciales a incluirse en un modelo de educación pertinente a la realidad. La educación intercultural se considera como una política de inclusión que afirma la validez de las diferencias y de las identidades, en el contexto de la Costa Caribe nicaragüense de cada uno de los pueblos 
indígenas y afrodescendientes, que apuntala cambiar las desigualdades injustas y las homogeneidades excluyentes (Venezia, 2003, p. 53).

Gracias a este tipo de educación intercultural las niñas y los niños se están educando alrededor de la diversidad que nos caracteriza: en lo cultural, lingüístico, social, espiritual, político y jurídico.

\section{Materiales y métodos}

La metodología que se utilizó fue cualitativa en el paradigma de la acción-reflexiónacción. Se identificaron los grupos de interés que sirvieron como informantes claves. Esto nos permitió valorar las distintas percepciones que tienen los pobladores sobre este tema y su protagonismo en el rescate de las creencias, costumbres y cultura de la comunidad.

Se realizó los grupos focales y entrevistas donde participaron diferentes personalidades, jóvenes, adultos y ancianos de ambos sexos.

Los resultados fueron leídos, analizados y organizados en base a creencias, costumbres en los procesos históricos de la isla. En esta etapa se realizó una discusión con algunos educadores de la isla. Por la forma se utilizaron métodos de historia oral, porque fue un trabajo de recopilación de los conocimientos que guarda la gente en su memoria o que todavía practican, a través de los relatos y cuentos que brindaron.

\section{Resultados y discusión}

\section{Un día en la vida de una mujer kriol}

Las mujeres kriol además de lavar, limpiar el hogar, el patio y cuidar los niños, tenían la preocupación o responsabilidad de decidir y preparar la comida de cada día. Además, tenían que ir al monte a cortar leña y buscar bastimento y coco en su pequeño huerto. Toda esta provisión era acarreada por la mujer, que generalmente cargaba las cosas encima de la cabeza. Pero también tenía que ir a la playa a esperar la entrada de los botes (ahora pangas) de la faena de pesca, acostumbrados a repartir entre los que aguardaban en la playa. Luego, una vez de regreso a casa, se ponía a cocinar su rondón y su gallo pinto. Cuentan que en ese entonces se rayaba hasta tres cocos para un buen gallo pinto de tres libras de arroz, y para el rondón se rayaba de seis a siete cocos. En ese entonces no se compraba el coco. El coco abundaba en la isla.

Luego, por las tardes se preparaba jani kiek (journey cake; tipo de queque de coco) o flat jak con té de hoja de limón, naranja o wail baazil. Esto era un típico preparativo 


\section{CULTURA INDÍGENA Y AFRODESCENDIENTE}

kriol para la cena. Después del desayuno la mujer por costumbre o por responsabilidad mantenía el fuego encendido debajo de la porra para que así se mantuviera caliente la comida del esposo hasta su regreso del campo.

Las mujeres kriol, por años y de generación en generación practicaban el intercambio de productos alimenticios básicos. Entre los vecinos se intercambiaban los productos. Por ejemplo, si uno no tenía banano y otra no tenía yuca se intercambiaban los dos productos y de esa manera se aseguraba un almuerzo más completo y con variedad para el día.

\section{Un día en la vida de un hombre kriol}

Nuestros ancestros eran hombres trabajadores, fieles sembradores y productores. Se levantaban a las cuatro de la mañana y se iban a sus huertos a sembrar. Pasaban todo el día en el monte y tomaban el camino de regreso como a las cinco de la tarde, un poquito antes de la puesta del sol. Era una rutina. Ellos solo tomaban su café o te de hojas por la mañana y a mediodía se podía ver a las señoras llevando sus comidas hasta donde se encontraban.

Cuando salían más temprano se ponían a limpiar el patio y a la hora mencionada anteriormente se paraban y descansaban. Luego se bañaban y al anochecer ellos ya se retiraban a dormir. Se cree que por eso los hombres eran fuertes, sanos y saludables, porque protegían su salud. Mientras ahora, según lo observado por los informantes, hoy en día esta generación no practica nada de esto ni otras costumbres anteriores, más bien discriminan la forma de vida de los ancestros.

\section{Costumbre posparto}

La mujer después de parir no cocinaba para sus esposos. Los hombres de ese entonces miraban a su mujer después de parir con asco, como sucias y no les permitían tocar nada. Era así hasta después de tres meses. Como no había electricidad y cuando no se tenía kerosén, la luz utilizada para el cuido del bebé era aceite de coco con algodón puesto en un plato. Se dice que se encendía esto porque no tira mucho humo.

\section{Forma de comunicar sobre el fallecimiento y entierro de una persona}

Entre los kriol la comunicación sobre el fallecimiento y entierro se hacía de una manera muy rápida y amistosa. Cuando una persona moría, no importaba la hora o el día, uno de los vecinos o un hombre montado a caballo partía de la casa del difunto gritando: "Se murió el Sr. xx y su entierro será tal día a tal hora". Con el tiempo un hombre conocido como Willy asumió esta responsabilidad como propia y de manera voluntaria. Él iba avisando casa por casa cuando moría alguien. Sin embargo, hay que tomar en cuenta que en ese entonces Corn Island era menos poblado. 
Ahora, dicen los entrevistados, con el aumento de la población todas esas buenas costumbres se han ido con el viento. La gente vive tan ocupada que, hoy en día las personas fallecen, son sepultadas y uno se entera hasta mucho tiempo después.

\section{Preparación de un cuerpo después de la muerte}

Una costumbre sobresaliente del pueblo kriol fue la preparación del cuerpo de una persona después de su muerte. Según nos relataron este proceso se realizaba de la siguiente manera:

La fruta llamada Seebl Arinj o betaam swiit fue usada en buenas cantidades para bañar al muerto. También se usaba cal. Ésta se ponía debajo de la cama en una porra. En el estómago se ponía café en grano y el muerto podía permanecer perfectamente dos o tres días esperando el sepelio. Hoy en día se acostumbra el uso de otros métodos para mantener el cuerpo de un muerto, y por la cantidad de días que se quiere. Entre estos mencionamos la morgue y la inyección de la formalina. La práctica tradicional ya no es practicada.

\section{Sepultura y velorio}

Cuando terminaban de darle cristiana sepultura al muerto, se venían a la casa de los familiares dolientes amigos o familiares de estas personas a hacerle compañía y permanecían con ellos por nueve días. Mientras que otros visitaban la casa con regularidad para ver como estaban las personas dolientes y para consolarlas. Cuando hacían el velorio, todos los vecinos venían a ayudar con la limpieza y preparación del jani kiek y café que era preparado en casa de uno de los vecinos. También se repartía licor.

En Corn Island no se practicaba el Nain Nait ("La novena noche"). Pasados dos o tres semanas, o cuando los familiares en luto lo consideraban oportuno, sacaban todas las pertinencias de la persona muerta y las quemaban, regalaban o las guardaban, pero nunca las usaban.

\section{Limpieza}

Era una costumbre entre los kriol que todos los días el patio se manejara limpio y que brillara. Sin embargo, el día sábado era un día especial y dedicado a la limpieza general. Los niños y las niñas tenían que ir a la playa a traer arena; eran dos tipos de arena, una fina y una gruesa, y tenían que echarla por todo el patio. Pero había una temporada más importante en cuanto a la limpieza: la Navidad. Los padres y las madres ponían a los niños a limpiar el patio y se tenía que traer arena gruesa de la playa y poner lo más que se podía en la parte frontal de las gradas porque decían que si Santa llegaba y no encontraba la arena blanca, no entraba a la casa a dejar los regalos. Por otro lado, era una alegría para la niñez encontrar las huellas que dejaba Santa a su paso por el 
patio y la casa. Las niñas y los niños tenían que dormir temprano, porque si no, corrían el riesgo de que Santa no pasara y no dejara regalos. En estos tiempos no había servicio de energía eléctrica. Era fácil acostarse temprano y levantarse temprano para encontrar la sorpresa del regalo de Santa.

\section{El día domingo}

Para el pueblo kriol, un día para estar con la familia era el día domingo. Todos se reunían donde un miembro especial, generalmente la madre y allí pasaban el día.

Los días domingos todos se iban a misa, era un día sagrado para todos. No se acostumbraba cocinar los domingos. Una vez de regreso de la misa o culto comían, pero la comida era preparada desde el día sábado. Era común preparar queque de yuca, quequisque, maíz, pescado frito, pan, jani kiek, etc.

Los entrevistados observan que hoy en día a la juventud muy poco le interesa ir al culto o a misa. Prefieren estar en un estadio viendo un juego, estar en la playa o en un bar.

\section{Semana Santa}

Durante la Semana Santa no se cocinaba ni se comía carne. Para nuestros ancestros la Semana Santa era algo sagrado. Se conservaba un respeto profundo para la semana. No se acostumbraba comer carne porque se decía que era el cuerpo o un pedazo del cuerpo del Señor Jesucristo. La sangre recordaba como su sangre brotaba de su cabeza. Ellos comían de todo que no llevara sangre, productos tales como huevos, pescado, frijoles y pan.

Hoy en día, piensan los informantes, esta generación no respeta ni práctica muchas de las costumbres de nuestros ancestros. Más bien, hacen todo lo contrario, la Semana Santa es aprovechada como una semana vacacional y de festejos, no como una semana de penitencia y para los asuntos propios de la iglesia cristiana.

\section{La Navidad}

La Navidad también era un día para pasar en familia, con las amistades y con los vecinos. Cuando se acercaba el tiempo de la Navidad, todos preparaban sus comidas, dulces y otros productos tradicionales.

Se preparaba los queques de banano, quequisque, maíz, fruta de pan, bred pudín (torta de pan) y también bebidas como jinjabier (bebida de jengibre). Todo era preparado días antes del 25 de diciembre. El propio 25 de diciembre se repartía la comida 
entre vecinos, familiares y amistades; acostumbraban ir de casa en casa saludando y dejando las delicias, y al mismo tiempo recibían sus regalos (comidas).

Al comparar las prácticas de hoy en día, según los entrevistados con más edad, no estamos ni cerca de las formas de convivencia de esos días. Hemos perdido todas esa buenas costumbres que nos inculcaron de pequeño. La vida se pasa tan ocupada que ni tenemos tiempo para saludar a nuestros seres queridos, menos practicar lo bello que ellos nos enseñaron.

\section{Vestimenta}

Las mujeres kriol acostumbraban usar el vestido largo con manga larga y cuello alto hecho de tela gruesa. Usaban una kanka debajo del vestido. Fabricaban la ropa interior usando la tela manta, con elástico en la cintura, la parte de las piernas llegaba hasta la rodilla y también llevaba elástico. Se acostumbraba amarrar el pelo.

Los hombres solían usar una camisa manga larga, el pantalón medio largo y siempre un sombrero.

Usaban todo igual, con la excepción de que acostumbraban clasificar la ropa de uso diario, de la ropa para estar en la casa y la ropa de salir a la calle. Además había la ropa para uso en ocasiones especiales, incluyendo la ropa para ir a misa. Las mujeres siempre se tapaban la cabeza para ir a la iglesia.

En ese entonces un hombre no podía ver las piernas menos la espalda de las mujeres, porque la forma como se vestían no lo permitía. Los informantes observan que hoy en día todo es diferente. La gente camina con muy poca ropa, casi andan desnudas por las calles. Se dice que "...cuando un hombre miraba pasar a una mujer se moría de la inquietud por ver lo que llevaba debajo de tanta ropa. Pero hoy en día miran todo y no le atrae mucho lo que está al aire libre."

\section{Construcción de viviendas}

Las casas eran construidas de caña y/o bambú. Lo partían por la mitad, lo colocaban bien apretados, fuerte y de fino acabado. Una vez terminada la casa la forraban con papel decorativo o papel café y así quedaba bonita y arreglada. El techo era de una palmera especial. Estas casas podían durar hasta treinta años, si los ratones no entraban al techo. El piso era de tierra y se echaba arena en el piso. Todos los sábados tenían que echar arena nueva al piso de tierra. En esos tiempos tenían madera pero sólo alguna gente podía tener casas de madera. Construir una casa era momento de compartir responsabilidad y solidarizarse en el trabajo. Cuando una persona tenía que construir una casa, la gente venía y ayudaba a la persona. 
En aquellos tiempos se construían dos casas, la más grande servía como dormitorio y la otra para la cocina. Pero las cocinas eran grandes, con mesas de comedor y un fayahaat (Fogonero). Al anochecer, la gente dejaba todos los utensilios en la cocina y la cerraba. Nadie molestaba ni tocaba sus cosas. No había luz eléctrica así que tenían que cocinar su cena temprano o si la noche llegaba usaban lámparas o linternas. Dice Miss Orpha que su tía hacía nacatamales para vender y ella los dejaba afuera hasta el día siguiente. Si un vecino llegaba a la casa de ella y ella estaba dormida, agarraba el nacatamal y al día siguiente pasaba y le pagaba por la cantidad de nacatamales que había tomado.

Había mucha honestidad. La gente era responsable y, sobre todo, muy trabajadora.

\section{Compartir}

La señora Helen White recuerda que a la gente le gustaba compartir, esto se practicaba mucho. Es por eso que, hasta hoy en día se dice que todavía tienen ese hábito.

Cuando venía visita a la isla, la gente de la isla ofrecía comida, casa y cama donde dormir. Cuando llegaba el tiempo de regreso a sus lugares, a estos visitantes se le ofrecía regalos, provisiones y cosas propias de la isla para que se llevaran.

Todos los fines de semana hacían queques, pan, jani kiek y bebidas de soril (Hoja de Jamaica) o jinja bier. El domingo compartían con los vecinos y todos repartían lo que habían preparado. Si alguien llegaba de visita a la casa se le ofrecía algo de lo que se había preparado. Cuando las personas destazaban un animal, sea cerdo, tortuga, vaca, repartían la carne a las personas del barrio. A veces cuando venían personas de otro barrio se les vendía; pero, si eran amigos no tenían que comprar. En otras palabras casi no se vendía, se regalaba.

No solamente se compartía comida, si no también utensilios de cocina. Si una persona necesitaba hornear y no tenía porra, podía conseguir una prestada del vecino. Cuenta el señor Rob que una vez su mamá prestó de su vecina una porra para hacer aceite de coco porque ellos no tenían una porra grande. Cuando su hermana fue a devolver la porra, la dueña dijo: "Esta no es mi porra! Vaya y traiga la mía." La hermana, quien era una niña en ese entonces, fue y cambió la porra. Cuando regresó donde la vecina, ésta dijo: "Ahora si, ésta es mi porra!"

\section{Formas de entretenimiento}

En años anteriores, además del trabajo, en los tiempos libres y especialmente cuando era luna llena, las personas iban a pasear a caballo. Hacían carreras de caballo e iban a pasear a otros barrios en la noche. Una forma especial de entretenimiento eran los cuentos. Nuestros abuelos nos contaban cuentos y adivinanzas. Y, cantaban. 
Suoshal ("social") consistía en un baile. Llegaban las mujeres y los hombres y bailaban al son de música viva. Los instrumentos utilizados eran la guitarra, el mandolín y el wash tob (Tina de lavar). Se bailaba shatiis, rumba, polka, merengue, samba, walts y conga. Bailaban las parejas y cuando terminaban de bailar el hombre tenía que ofrecer algo de comer a la mujer. En una mesa puesta en el salón del baile, se colocaba una variedad de comida. Había carne, soda kiek, queque de quequisque y pan, entre otras cosas. También había bebida como soril, jinjabier, etc. Así todos los hombres tenían que comprar algo para la mujer.

Pink Tea Party era otro baile. Consistía en que todo era decorado de color rosado. Hasta la comida y vestuario de la gente era rosado. Se servía comida y bebida gratis. Todos bailaban. Los más ancianos preparaban ron casero de maíz y servían el ron sólo cuando los viejitos tenían sus fiestas. Cuando invitaban a una joven o un joven a una fiesta, un adulto lo acompañaba. Cuando terminaba la fiesta, regresaba a su hogar acompañado por las personas mayores. Además, las fiestas terminaban temprano. Vestirse para ir a una fiesta no significaba usar ropa atrevida. Los vestidos o faldas quedaban por debajo de la rodilla y las blusas tenían que ser con mangas.

\section{Creencias de la población kriol}

En lo siguiente presentamos la parte de las creencias de la población kriol en Corn Island.

\section{El pescado Uol waif}

Dicen nuestros ancestros y todavía entre los kriol persiste la creencia de que de todos los peces en el océano hay uno que se llama Uol waif, alrededor del cual hay un gran secreto. Se cree que la gente foránea, si lo comen frito o en rondón, no puede dejar la isla y si logran salir tienen que volver y con intenciones de quedarse.

Por esta creencia mucha gente, cuando se le ofrece pescado, lo primero que te preguntan es si es Uol waif.

\section{Cuidados antes y después de embarazo}

La mujer embarazada en tiempos anteriores se cuidaba muy bien. La partera realizaba una labor de control y cuido aún antes del parto. Sobaba a la embarazada si presentaba dolor y si el feto estaba en una posición difícil. Controlaba la fecha del parto con los cambios de la luna. Se observaba que si la mujer parirá con la luna llena, el parto era más difícil para ella; porque su bebé sería más grande debido a la fase de la luna.

Después del parto, la mujer no volvía a ver la luz del sol hasta después de tres meses. Se cuidaba tan bien que se pudo mantener en su cuarto encerrado por tres 
meses. No se peinaba, se arropaba muy bien, usaba calcetines y se fajaba. En cuanto al aseo personal, el baño consistía sólo en asearse las partes íntimas con agua tibia, producto del cocimiento de diferentes hojas curativas y aromáticas. La partera le sobaba, aplicaba masajes y apretaba la espalda para que se cerraran bien los huesos de la espalda. Durante todo ese período no salía del cuarto para nada.

Se cree que debido a estas prácticas y el cuidado tan especial que recibían las mujeres en el período de posparto ellas vivían hasta edad muy avanzada manteniendo una buena salud. Acostumbraban tener muchos hijos pero eran saludables. La diferencia de esa época con estos tiempos es muy marcada. La mayoría de las mujeres después de dar a luz salen ya el día siguiente del parto. Tampoco tienen cuidado en la forma de vestir, generalmente utilizan poca ropa e inclusive comienzan a frecuentar los lugares de baile poco tiempo después del parto.

Mientras que debido a las prácticas de hoy en día y los descuidos y desmanes, se cree que esta generación se autodestruye de una manera rápida. Esto es por no tomar las buenas lecciones que nos han dejado nuestros ancestros. Con solamente un hijo dan la apariencia de haber tenido varios partos. Y, en comparación con la salud que mantenían las mujeres en épocas anteriores es enorme la diferencia, hay muchos casos de muertes maternas, casos de cáncer uterino y de mama y mucho deterioro físico.

\section{Cuidado con los recién nacidos}

En la cultura kriol se cree que los recién nacidos no deben ser expuestos a afectaciones externas. Porque ciertas personas al ver a un recién nacido o entrar en contacto con él, le afectan fisiológicamente. Por ejemplo les dan lo que comúnmente se conoce como "pujo" o estreñimiento. Por otro lado, una persona bajo las influencias del licor no debe ver a un niño recién nacido, aunque fuera el padre.

También se cree que un niño, si todavía no está bautizado, no puede ir a un entierro. Mientras que si un familiar tiene que ir al cementerio, éste debe quitarse la ropa antes de entrar a la casa donde hay un recién nacido.

Todo esto no es muy observado hoy en día. Más bien ahora los niños al nacer inmediatamente comienzan a realizar movimientos que antes no hacía un recién nacido y desarrollan cambios y actividades a muy temprana edad.

\section{El mar en Viernes Santo}

Era prohibido bañarse el Viernes Santo en el mar. ¿Por qué? Decían que si se metía en el mar este viernes y si se llegaba a mediodía, se convertían en pescado o sirena. Esta creencia fue practicada y manejada con delicadeza porque aseguran los ancianos el cien por ciento que pasaría esto. 


\section{Cura del asma}

Entre el pueblo kriol se cree que una forma de curar a las personas asmáticas consiste de que el día Viernes Santo a mediodía se pone a una persona a posar contra el tronco del árbol llamado fisiknat y se le corta el pelo en el tronco del árbol. El pelo queda incrustado en el árbol, y mediante va creciendo el árbol, la enfermedad va desapareciendo. Esta es una de las creencias que todavía se conserva y se practica.

\section{Señales y milagros}

\section{Perros que aúllan}

Cuando los perros aúllan de noche se dice que es señal de que alguien va morir y que estos animales ven o perciben estos fantasmas. Porque aparentemente el espíritu deambula antes de la muerte física de la persona. Sin embargo, estos mismos animales cuando ladran viendo hacia el norte es señal de que va a soplar fuerte el viento, en otras palabras, es señal de un mal tiempo.

Todavía hay personas entre el pueblo kriol que conservan esas creencias y que aprenden a observar y conocer los cambios en el tiempo por estas creencias.

\section{Laafin bord ('pájaro riente')}

Este pájaro, si vuela por encima de la cabeza de alguien de noche, está dando el aviso de que alguna joven de la casa está embarazada. Las personas de la vecindad se preocupaban mucho cuando esto ocurría. Por otro lado, esto despertaba enojo y sospecha entre las madres y los padres del lugar. Esta fue una de las creencias más marcadas entre los kriol. Porque era y daba por hecho que así era la situación. Hace mucho que no se escucha a este pájaro. Entonces, esta creencia está casi olvidada.

\section{Canto del gallo}

Se cree que los gallos que cantan en las primeras horas de la noche están dando aviso de que algo malo o trágico va ocurrir. También es señal de que el clima va cambiar. Esa creencia todavía se mantiene, aunque es más conocido y observado entre las personas más ancianas.

\section{La escoba y la sal}

La escoba es utilizada para correr a una persona de la casa cuando no es deseada esta visita. ¿Cómo funciona? Se coloca la escoba en posición invertida detrás de la puerta con un tenedor insertado en la parte de barrer con un puño de sal. Era muy común hacer esto inclusive con las visitas que se prolongaban por mucho tiempo. Esta práctica también ha caído en desuso entre las personas más jóvenes. 


\section{CULTURA INDÍGENA Y AFRODESCENDIENTE}

\section{La mariposa}

Las mariposas son animales que avisan sobre una visita a la casa. Este aviso les permitía a las personas utilizar una escoba puesta detrás de la puerta para evitar la visita cuando no era deseada o cuando creían que no estaban en condiciones de recibir alguien en la casa.

\section{El gato}

Cuando un gato se está limpiando la cara es señal de que va llover o viene visita.

\section{Predicción utilizando un huevo y un vaso}

Se cree que para el día Viernes Santo, si revienta un huevo en un vaso con agua desde las seis de la mañana dejándolo reposar hasta mediodía, cuando se destapa se habrá formado una figura. Si la figura se asemeja a la de una iglesia, es señal de que uno pronto se casará. Mientras que si por ejemplo, la figura es de un ataúd, es señal de que alguien de la familia muy pronto morirá. De igual manera pueden salir figuras indicando viajes u otras cosas.

\section{El trueno en el mes de enero al inicio del año}

Cuando se escuchaba el trueno en el primer día del año nuevo y durante los primeros días del mes de enero, nuestros ancestros predecían un año de muchos fallecimientos. Decían que habría rich grievyaad; traducido al español significa abundancia para el cementerio. Esta creencia todavía persiste entre la mayoría de los kriol, es una forma de predecir muertes numerosas entre la población del lugar. Quiere decir que los primeros días del año nuevo son muy observados por la gente.

\section{Picadura de pies}

Relacionado a la muerte está también la creencia de que cuando a alguien le pican los pies, es señal de que pronto visitaría el cementerio.

\section{Doce primeros días de enero y la predicción del clima}

Otro motivo por el cuál los primeros días del mes de enero son muy observados por la gente, tiene que ver con la predicción sobre el clima de los doce meses del año. En la Costa Caribe sólo hay dos estaciones en el año, la estación lluviosa y la de verano. Los primeros doce días del mes de enero son comparados con los doce meses del año. El clima de cada día representa el clima de los meses correspondientes. Sí hacia sol 
el primer día esto era señal de que enero sería un mes de sol y un poco de lluvia. Si para el segundo día llovía, era una señal de que febrero sería un mes de lluvias y así sucesivamente hasta observar los doce primeros días de enero.

\section{Descanso de los espíritus}

Cuando el espíritu de una persona no está descansando en paz, el espíritu sale, deambula y molesta a las personas vivas. Para que el espíritu no siga molestando o penando, se tiene que llevar una pana con frijoles cocidos a la tumba y hablar con el muerto, se le dice: cuando crezcan estos frijoles puedes volver. Esta es una cura para que cualquier espíritu deje de molestar.

\section{Conclusiones}

Las creencias y costumbres del pueblo kriol aún permanecen y están vivas entre muchos pobladores de la isla, quienes han logrado conservarlas, quizás porque tuvieron la dicha de vivir parte de sus vidas entre nuestros ancianos, donde predominaba el espíritu de compartir, la solidaridad y en muchas vivencias la sinceridad entre la población. Esto no quiere decir que fueran seres perfectos, pero si había un alto grado de sensibilidad humana.

Con el paso del tiempo estas costumbres, creencias y tradiciones fueron perdiendo su valor real. Se comenzó a darle menos importancia a estos valores positivos que poseían nuestros ancestros.

El progreso y el avance tecnológico son significativos, porque ofrece mejores formas de sobrevivencia para los pobladores. Ofreciéndole mayores niveles de seguridad en vivienda, salud, transporte, educación, etc. Sin embargo, en muchos aspectos no sólo podemos pensar en avances sin medir el impacto que puede traer para la cultura de los pueblos. El concepto de progreso y avance tecnológico debe ser estudiado y analizado frente a la cultura de los pueblos y cómo esto puede destruir tradiciones y prácticas sustanciales de los mismos. La falta de este tipo de análisis en muchos casos nos ha limitado conocer cómo fueron y cómo vivieron nuestras abuelas y abuelos. Nos privó de la oportunidad de conocer sus perspectivas sobre la vida, la naturaleza, los valores y sus conocimientos en general.

Es importante retomar algunas de las tradiciones de nuestros antepasados, porque nos permitirá rescatar valores que nos podrían dar una respuesta a grandes problemas sociales de nuestra sociedad. Pérdidas que ahora se observa en la destrucción moral, espiritual y física de la población. 


\section{Lista de referencias}

Hodgson, Oliver (2007). Cultura de la Costa Caribe de Nicaragua. Compendio - Licenciatura en EIB. URACCAN.

Rizo, Mario (2003). Cultura. Managua: Terra Nuova.

Venezia, Paolo (2003). Educación Intercultural y Plurilingüe. Managua: Terra Nuova. 